$$
\text { col }
$$

\title{
LEACH RESISTANCE PROPERTIES AND RELEASE PROCESSES FOR SALT-OCCLUDED ZEOLITE A*
}

by

ANL/CMT/CP-77755

M. A. Lewis, D. F. Fischer, and J. J. Laidler

DE93 005573

\author{
Chemical Technology Division \\ Argonne National Laboratory \\ 9700 South Cass Avenue \\ Argonne, Illinois 60439
}

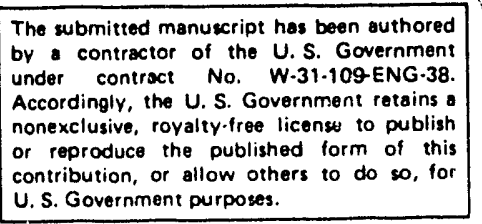

\section{DISCLAIMER}

This report was prepared as an account of work sponsored by an agency of the United States Government. Neither the United States Government nor any agency thereof, nor any of their employees, makes any warranty, express or implied, or assurnes any legal liability or responsibility for the accuracy, completeness, or usefulness of any information, apparatus, product, or process disclosed, or represents that its use would not infringe privately owned rights. Reference herein to any specific commercial product, process, or service by trade name, trademark,

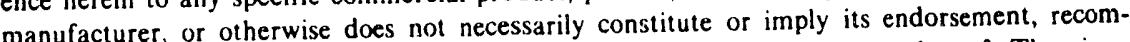
mendation or favoring by the United States Government or any agency thereof. The views and opinions a authors expressed herein do not necessarily state or reflect those of the United States Government or any agency thereof.

"Work supported by the U.S. Department of Energy, Nuclear Energy Research \& Development Program, under Contract W-31-109-Eng-38. 


\title{
LEACH RESISTANCE PROPERTIES AND RELEASE PROCESSES FOR SALT-OCCLUDED ZEOLITE A
}

\author{
M. A. LEWIS, D. F. FISCHER, AND J. J. LAIDLER
}

Argonne National Laboratory, 9700 South Cass Avenue, Argonne, Illinois 60439

\section{ABSTRACT}

The pyrometallurgical processing of spent fuel from the Integral Fast Reactor (IFR) results in a waste of $\mathrm{LiCl}-\mathrm{KCl}-\mathrm{NaCl}$ salt containing approximately $10 \mathrm{wt} \%$ fission products, primarily $\mathrm{CsCl}$ and $\mathrm{SrCl}_{2}$. For disposal, this waste must be immobilized in a form that it is leach resistant. A salt-occluded zeolite has been identified as a potential waste form for the salt. Its leach resistance properties were investigated using powdered samples. The results were that strontium was not released and cesium had a low release, $0.056 \mathrm{~g} / \mathrm{m}^{2}$ for the 56 day leach test. The initial release (within 7 days) of alkali metal cations was rapid and subsequent releases were much smaller. The releases of aluminum and silicon were 0.036 and $0.028 \mathrm{~g} / \mathrm{m}^{2}$, respectively, and were constant. Neither alkali metal cation hydrolysis nor exchange between cations in the leachate and those in the zeolite was significant. Only sodium release followed $t^{0.5}$ kinetics. Selected dissolution of the occluded salt was the primary release process. These results confirm that salt-occluded zeolite has promise as the waste form for IFR pyroprocess salt.

\section{INTRODUCTION}

The Integral Fast Reactor (IFR) is an advanced reactor concept under development at Argonne National Laboratory (ANL). The pyrometallurgical processing of spent fuel from the IFR will result in a waste $\mathrm{LiCl}-\mathrm{KCl}-\mathrm{NaCl}$ salt containing approximately $10 \mathrm{wt} \%$ fission products, primarily cesium and strontium, as chlorides [1]. The alpha activity of the salt will be very low, $<100 \mathrm{nCi} / \mathrm{g}$. A Waste Handling Program is underway at ANL to develop a waste form for this salt that meets acceptance criteria for disposal and a waste-form fabrication process that is relatively simple. The salt meets the definition of High Level Waste in 10CFR 60.2, and therefore, must meet the acceptance criteria for disposal in a geologic repository. The salt is to be processed "as is" (i.e., as a molten chloride salt) so that chemical conversion and separation steps are avoided. Since the waste salt is water soluble and affected by radiation [2], a new type of waste form, which immobilizes the salt and improves its radiation stability, is required if acceptance criteria are to be met. Also desired is the efficient loading of the waste salt, i.e., effectively concentrating the salt's radionuclides in the Immobilization matrix.

Salt-occluded zeolites have been identified as promising waste forms [3]. Salt-occluded zeolites are similar to a class of naturally occurring minerals, the feldspathoids. These are aluminosilicates which contain cation-anion pairs within the pores of the structure.

Salt-occluded zeolites are formed when zeolites are equilibrated with molten salts $[4,5]$. Two types of reactions occur, salt occlusion and ion exchange. Salt occlusion is the inclusion of salt within the pores of the zeolite. This reaction is similar to the inclusion of water by dehydrated zeolites. Ion exchange in molten salt is similar, in principle, to that in aqueous solution. Ions in the molten salt or aqueous salt solutions are exchanged with the chargecompensating cations in the zeolite's framework. Zeolite A reacts favorably with molten IFR waste salt [3]. Before treatment with the molten salt, the composition of the unit cell of zeolite $A$ is $\mathrm{Na}_{12}\left[\left(\mathrm{AlO}_{2}\right)_{12}\left(\mathrm{SiO}_{2}\right)_{12}\right]$. After treatment, the sodium concentration of the zeolite is reduced from 16.2 to $<1$ wt\%. The weight of the zeolite increases by $36 \%$ from ion exchange and salt occlusion. Strontium and cesium are preferentially sorbed from the salt and 10-12 cation-anion pairs are occluded. Formulas of reaction products are tentative at this time because exchanged and occluded cations have not been distinguished. Results from other studies indicated that salt-occluded zeolites do not function as ion exchangers in aqueous solution [6] and that, in some cases, occluded salt is not readily dissolved in water $[7,8]$. The 
leach resistance of IFR salt-occluded zeolite A powders was measured in a series of preliminary experiments [3]. The leach tests were run for seven days at $90^{\circ} \mathrm{C}$ in deionized water. For these tests, the leachabilities were low, $<10^{-5} \mathrm{~g} / \mathrm{m}^{2} \mathrm{~d}$ for strontium and $6.6 \times 10^{-3}$ $\mathrm{g} / \mathrm{m}^{2} \mathrm{~d}$ for cesium. These results showed that the concept of the salt occluded zeolite as an immobilization matrix for the IFR waste salt is promising and further work is justified.

We conducted further leach tests to obtain preliminary information on elemental release mechanisms. From leaching studies of glass, factors which affect elemental release have been identified [9]. Two important factors, leaching time and composition, were addressed in the present study of the leach properties of salt-occluded zeolite A powders. The time dependence for elemental release was measured for up to 56 days. The effect of different waste loadings was also considered. These data not only provide information on the release mechanisms from the powdered samples but also guide the development of the densification procedure required to produce the solid, monolithic waste form required for acceptance for repository disposal.

\section{Experimental}

Sample Preparation. Molten salt-zeolite equilibrations were performed in a column contained in a $400^{\circ} \mathrm{C}$ furnace in an argon glovebox. Approximately $40 \mathrm{~g}$ of molten salt was poured into the column containing about $12 \mathrm{~g}$ of zeolite. The salt was allowed to percolate through the column under gravity. The salt and zeolite mixture was then quenched. The column was divided into four approximately equal sections, the top, upper and lower middle, and the bottom. Each was broken into small chunks, which were quickly washed using vacuum filtration to remove the soluble salt on the zeolite surface. The washed powders were dried at $110^{\circ} \mathrm{C}$ until constant weight was obtained. Further details of the apparatus and chemicals will be published elsewhere [3].

Analysis Methods. Inductively coupled plasma-atomic emission spectroscopy (ICPAES) was used to determine $\mathrm{Al}, \mathrm{Ba}, \mathrm{K}, \mathrm{Li}, \mathrm{Na}$ and $\mathrm{Sr}$ content. In a few samples, silicon was determined gravimetrically. Atomic emission spectroscopy (AES) was used to analyze samples for cesium, and ion chromatography (IC) for chloride and iodide ions. The particle size distribution of the salt-occluded zeolite powders was determined by Elzone particle size analysis. (In the Elzone technique, the particle size is determined by measuring the volume of electrolyte displaced as the particle passes through a small opening. Approximately 200,000 particles are used in an analysis from which the particle size distribution is obtained.) This techrique gives the external surface area of the particles, but not their internal surface area.

Leach Test Method. The leach resistance of the powdered salt-occluded zeolites was measured in static leach tests at $90^{\circ} \mathrm{C}$, following the Product Consistency Test (PCT) procedure as much as possible [10]. The modifications to the procedure were in sample size and in the ratio of the volume of leachant to the mass of solids $(\mathrm{V} / \mathrm{m})$. The average particle size was about $3.8 \mu \mathrm{m}$. Approximately $0.3 \mathrm{~g}$ of sample was used in each leach test because only a limited amount of material was available. The ratio between the volume of leachant and the mass of solids, $\mathrm{V} / \mathrm{m}$, in most of the tests was $100 \mathrm{~mL} / \mathrm{g}$ so that there was sufficient leachate for the various analyses. One test was done with a V/m ratio of $10 \mathrm{~mL} / \mathrm{g}$, which is the typical V/m ratio for the PCT tests.

\section{RESULTS AND DISCUSSION}

\section{Effect of Time and Release Processes}

A series of leach tests was conducted to obtain preliminary information on elemental release mechanisms from salt-occluded zeolite $A$. The time dependence was investigated by running leach tests for $3,7,14,28$ and 56 days. The salt-occluded zeolite composition is given by column position in Table I. The samples used in these leach tests were from the upper middle position. The leachates were analyzed for cation and anion content. The 
normalized mass loss was calculate from the equation, $N L=C_{i} V / f_{i} A$ where $C_{i}$ is the concentration of the element $i$ in the achate in $\mathrm{g} / \mathrm{mL}, V$ is the volume of leachate in $\mathrm{mL}, f_{\mathrm{i}_{2}}$ is the fraction of the element $i$ in the solk nitially, and $A$ is the surface area of the solid in $\mathrm{m}^{2}{ }^{2}$ The surface area of the powders was cis lated as $0.75 \mathrm{~m}^{2} / \mathrm{g}$ using an average particle size of $3.8 \mu \mathrm{m}$ and assuming cubic particles and a density of $2.1 \mathrm{~g} / \mathrm{cm}^{3}$. The normalized elemental mass Inss is plotted versus time in Fig. 1 for the cations and Fig. 2 for the anions.

\begin{tabular}{|c|c|c|c|c||}
\hline \multicolumn{5}{|c|}{ Table I. Composition of a Column of Salt-Occluded Zeolite $A^{a}$} \\
\hline Component & \multicolumn{4}{|c||}{ Column Position ${ }^{\mathrm{b}}$} \\
\hline $\mathrm{Al}$ & $\mathrm{Top}$ & Upper Middle & Lower Middle & Bottom \\
\hline $\mathrm{Ba}$ & 12.5 & 12.8 & 13.4 & 13.9 \\
\hline $\mathrm{Cs}$ & 7.55 & 4.97 & 0.48 & 0.14 \\
\hline $\mathrm{K}$ & 5.7 & 6.7 & 8.2 & 6.8 \\
\hline $\mathrm{Li}$ & 5.20 & 6.0 & 6.96 & 7.62 \\
\hline $\mathrm{Na}$ & 3.64 & 4.15 & 4.47 & 4.66 \\
\hline $\mathrm{Si}$ & 0.71 & 0.77 & 0.86 & 0.91 \\
\hline $\mathrm{Sr}$ & 12.8 & $13.3^{\mathrm{c}}$ & 14.1 & 14.5 \\
\hline $\mathrm{Cl}$ & 3.39 & 0.85 & 0.006 & $<0.001$ \\
\hline $\mathrm{I}$ & 15.6 & 16.0 & 15.7 & 16.3 \\
\hline
\end{tabular}

\section{aElemental wt\%}

'Sample weights were $3.53,4.15,4.00$, and $3.17 \mathrm{~g}$ for top, upper middle, lower middle, and bottom positions, respectively.

${ }^{c}$ Estimated from the aluminum concentration and the measured aluminum and silicon ratios of the samples from the top and lower middle positions.

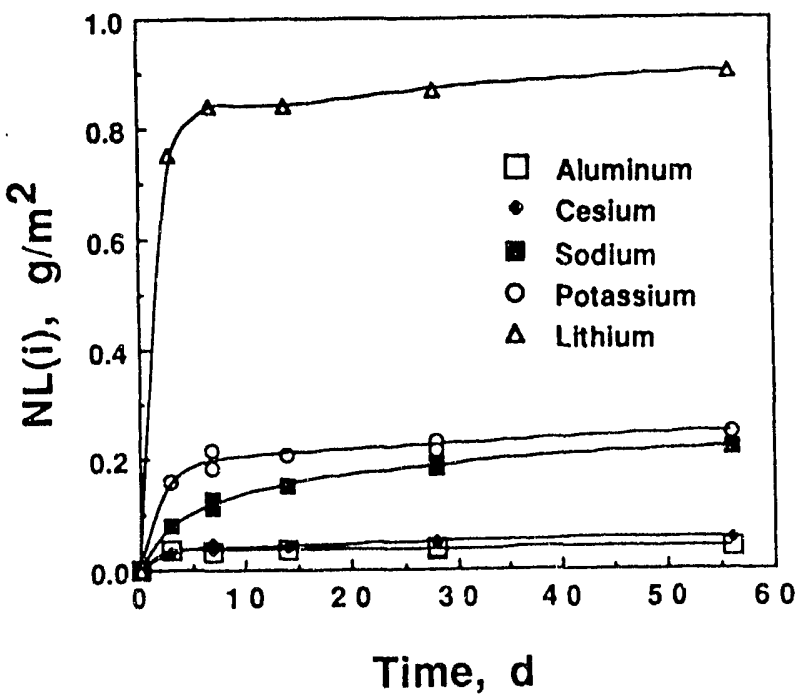

Fig. 1. Normalized mass losses (NL) for cations in salt-occluded zeolite $\mathrm{A}$ versus time in $90^{\circ} \mathrm{C}$ leach tests with deionized water.

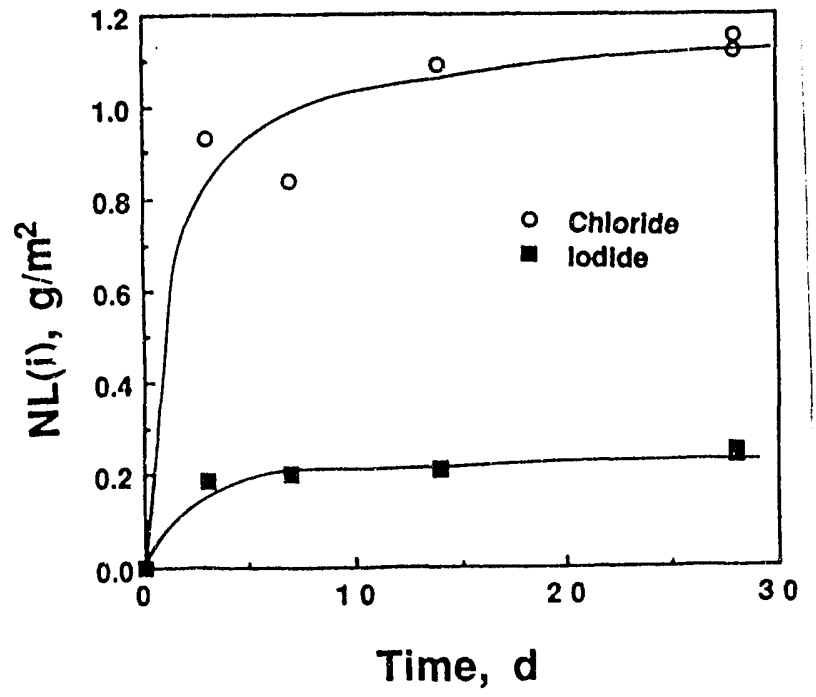

Fig. 2. Normalized mass losses for anion in salt-occluded zeolite $A$ versus time in $90^{\circ} \mathrm{C}$ leach tests with deionized water. 
Several observations were made from the data. The normalized mass loss for cesium was small, varying from 0.030 for three days to $0.056 \mathrm{~g} / \mathrm{m}^{2}$ for 56 days. The normalized mass losses for strontium and barium were not calculated because, in all of the leachates, their concentrations were below the ICP-AES detection limits of 5 and $20 \mathrm{ppb}$. The average normalized mass loss for aluminum was small $\left(0.036 \mathrm{~g} / \mathrm{m}^{2}\right)$ and constant within the $10 \%$ experimental error. The average normalized mass loss for silicon was also small $\left(0.028 \mathrm{~g} / \mathrm{m}^{2}\right)$ and constant within experimental error. The normalized mass losses for the other alkali metals were larger, increasing in the order $\mathrm{Na}<\mathrm{K}<\mathrm{Li}$. The normalized mass loss for chloride was greater than that for iodide. The initial mass loss was the largest for all of the components and subsequent losses were much smaller.

In studies of the alkali leaching from glass, two time dependencies for normalized mass loss have been observed, $t^{0.5}$ and $t$. In one model, these have been related to the microporous structure and the rate of diffusion of water $[9,11]$. If the mechanisms for alkali leaching from salt occluded zeolite and glass are similar and if the microporous structures are similar, one or both of these kinetics should be observed. However, the normalized elemental mass loss data in Figs. 1 and 2 do not fit linear curves. There is a large initial release, followed by a slow release of both cations and anions. Regression analysis of these data versus $\mathrm{t}^{0.5}$ showed that only sodium fit these kinetics. The release of the alkali metals ( $\mathrm{Li}, \mathrm{K}$, and Cs) does not fit the model for alkali leaching from glass, indicating that the release mechanisms, microstructure or rate of water transport through the zeolite are different. In bulk glasses, the void size is 2.2 to $2.4 \AA$. The aperture size of the sodium form of zeolite $A$, the starting material, is $4 \AA$. However, in salt-occluded zeolite $A$, the sodium was replaced by other ions and 10-12 salt molecules filled the cavities. The size of the aperture and the effect of the occluded salt on water transport were not known. The loss of the relatively large amounts of lithium and chloride ions suggest that water was able to penetrate the cavities and that the hydration energy of the occluded ions exceeded their binding energy to the aluminosilicate matrix.

The large initial release is associated with the dissolution of the occluded salt, as the concentrations of lithium and chloride ions are approximately equal and approach $0.02 \mathrm{M}$. This concentration represents about 65 wt\% of the total lithium, which is high but comparable to the amount of sodium lost from sphene glass-ceramic phases leached in $\mathrm{Ca}-\mathrm{Na}-\mathrm{Cl}$ brines [12]. Lithium has the highest normalized loss followed by potassium and then sodium. The hydration energies of lithium, sodium and potassium are 519, 406 and $322 \mathrm{~kJ} \mathrm{~mol}^{-1}$ [13]. The normalized mass loss for lithium and potassium follow the same order as the hydration energies, with sodium being an exception. One possible explanation is that sodium occupies a more stable site than lithium and potassium. The starting material in these experiments was the sodium form of zeolite $A$, and a small amount of sodium $(<1 \%)$ was not exchanged when the zeolite was treated with the molten salt. This "unexchangeable" sodium may have greater binding energy and, hence, greater leach resistance than the lithium and potassium. The $t^{0.5}$ kinetics may be fortuitous.

The normalized mass loss for cesium is lower than that of the other alkali metals. It is not known if this results from the lower hydration energy $\left(264 \mathrm{~kJ} \mathrm{~mol}^{-1}\right)$ [13], occupation of a more stable site, or steric effects. lodide release is also smaller than chloride release. Since the ionic diameters are 4.40 and $3.62 \AA$, respectively, a steric effect in the anion release is suggested. Neither strontium nor barium were detected in the leachates. These ions may occupy more stable sites in the zeolite than the Group I elements. There is some evidence that multivalent cations are incorporated into the aluminosilicate framework as charge compensating cations [14].

Another possible loss mechanism is ion exchange. However, ion exchange between lithium and potassium in the solution and cesium, strontium and barium in the zeolite is minimal from the data in Fig. 1. Ion exchange between the alkali metal ions and hydrogen ion, or cation hydrolysis, does not occur to an appreciable extent either. The $\mathrm{pH}$ of the leachates was measured and, though there was some scatter, the overall effect was that the $\mathrm{pH}$ decreased with time. The $\mathrm{pH}$ of the leachate in the 7-day and 56-day tests were 10.8 and 10.3, respectively. These results are under study.

As mentioned above the normalized mass loss for aluminum and silicon was the same within experimental error for these leach tests. Thus, the dissolution of these elements was solubility limited. Further evidence for this conclusion was that the normalized losses for these elements decreased at least tenfold when the $\mathrm{V} / \mathrm{m}$ ratio was reduced from 100 to $10 \mathrm{~mL} / \mathrm{g}$. The normalized losses for the alkali metals were about the same in the two types of leach tests. Similar results were obtained in room-temperature leach tests as well. 
The data in Figs. 1 and 2 appear to fit the equation for solution saturation,

$$
C_{t}=C_{s}\left(1-e^{-k t}\right)
$$

where $C_{t}$ and $C_{s}$ represent the concentrations (or equivalently, the normalized mass loss) at time $t$ and at steady-state, respectively and $k$ is the rate constant. However, the data do not fit the equation well. One reason may be that the initial dissolution was too rapid, as only one or two data points definad this release. Another reason may be that there are other loss mechanisms but these are masked by the predominant loss of occluded salt.

The effect of particle size on these leach test results has not been explicitly considered because only one distribution of particle size is currently available. It is possible that the large initial release observed in Figs. 1 and is 2 is partially caused by the dissolution of "small" particles or fines. (The particle size distribution was not Gaussian but was skewed toward the smaller sizes.) This will be considered in future studies.

\section{Effect of Composition}

The composition of the salt-occluded zeolite is determined by its method of preparation. In column experiments, the sample composition depends on the ion exchange properties of the zeolite and the position of the sample along the column length. The largest variation among the samples given in Table I was their divalent ion ( $\mathrm{Ba}$ and $\mathrm{Sr}$ ) concentrations, which were much higher in the top half of the column than in the bottom half. It was of interest to determine whether the leach resistance properties varied with composition. Thus, samples of each section were leached at $90^{\circ} \mathrm{C}$ for seven days in deionized water. The normalized mass losses are given for several elements in Table II. The largest effect was seen for cesium, as its normalized mass loss varied almost 100 -fold. Much smaller variations $(<2)$ were observed for the other elements. These data suggest that variations in the concentrations of divalent ions affect cesium release, possibly by changing the packing of the occluded salt or charge distribution within the cavity such that the release of cesium is retarded. Another reason may be that the cavities or entrances to the channel system may become blocked with relatively high concentrations of barium, thereby retarding release of the large cesium ion (ionic diameter, $3.4 \mathrm{~A}$ ) but having less effect on the other cations. A similar effect of barium was observed in hollandite [15]. The effect in the salt-occluded zeolite, though, has to be more than a simple steric effect because potassium is also present, and the potassium ion is about the same size as the barium ion. Increasing concentrations of potassium along the length of the column did not affect leach resistance.

\begin{tabular}{||c|c|c|c|c||}
\hline \multicolumn{5}{|c||}{ TABLE II. Normalized Elemental Mass Loss (NL) at Four } \\
Column Positions with Different Waste Compositions
\end{tabular}

${ }^{a} \mathrm{NL}$ for seven day, $90^{\circ} \mathrm{C}$ leach tests with deionized water.

bee Table I for composition. 


\section{CONCLUSIONS}

The results of the above leach tests were for very fine salt-occluded zeolite powders whose average particle size was $<4 \mu \mathrm{m}$, where surface effects are expected to predominate. Nevertheless, these results provide useful preliminary information concerning possible release mechanisms. These include the following: (1) release of strontium and barium is below detection limits, (2) release of cesium is low, (3) dissolution of the occluded salt is the predominant loss mechanism and primarily involves lithium chloride, (4) ion exchange of cesium, strontium, or barium in the zeolite with lithium and potassium in the solution is minimal, (5) the dissolution of the aluminosilicate matrix is solubility limited, indicating that the aluminosilicate framework is stable, and (6) leach resistance may be improved by the addition of large ions such as barium.

The release of relatively large amounts of $\mathrm{LiCl}$ indicates that water penetrated the three dimensional channel system of the zeolite powders. The other results suggest that the saltoccluded zeolite is a promising immobilization matrix for the IFR waste salt. Overall, these results indicate that the method for consolidating the powders into a solid monolith for nuclear waste disposal should be such that the three-dimensional channel system is no longer

continuous and the effective aperture size is reduced to less than the diameter of water, $2.8 \AA$. One method to accomplish this is to incorporate the salt-occluded zeolite powders into a second phase whose porous microstructure has apertures $<2.8 \AA$. Work is now underway to develop such a solid monolith.

\section{REFERENCES}

1. T. R. Johnson, M. A. Lewis, A. E. Newman, and J. J. Laidler, "Treatment of High-Level Wastes from the IFR Fuel Cycle," submitted to J. Am. Chem. Soc.

2. L. R. Pederson, "Chemical Implications of Heat and Radiation Damage in Rock Salt," Material Research Society Symposium Proceedings, 44, 701 (1985).

3. M. A. Lewis, D. F. Fischer, and L. J. Smith, "Salt-Occluded Zeolites as an Immobilization Matrix for Chloride Waste Salt," submitted to J. Am. Ceram. Soc.

4. M. Liquornik and Y. Marcus, Israel J. Chem., 6, 115 (1968).

5. M. Liquornik and Y. Marcus, J. Phys. Chem., 72, 2885 (1969).

6. M. V. Susic, N. A. Petranovic, and D. A. Mioc, J. Inorg. Nucl. Chem., 33, 2667 (1971).

7. R. M. Barrer, J. Chem. Soc., 127 (1948).

8. R. M. Barrer and W. M. Meier, J. Chem. Soc., 299 (1958).

$9 . \quad$ B. C. Bunker, "Waste Glass Leaching: Chemistry and Kinetics," Material Research Society Symposium Proceedings, 84, 493 (1987).

10. C. M. Jantzen, N. E. Bibler, D. C. Beam, W. G. Ramsey, and B. J. Waters, Standard Test Method Relative to Durability of Nuclear Waste Glasses: The Product Consistency Test (PCT). Savannah River Laboratory Report, WSRC-TR-90-539, Revision 2 (1991).

11. R. M. Barrer, Zeolites and Clay Minerals as Sorbents and Molecular Sieves, Academic Press, London (1978).

12. P. J. Hayward, D. C. Doern and I. M. George, J. Am. Ceram. Soc., 73, 544 (1990).

13. F. A. Cotton and G. Wilkinson, Advanced Inorganic Chemistry, Interscience, New York, (1972).

14. M. Liquornik, J. Inorg. Nucl. Chem., 33, 283 (1971).

15. D. R. Clarke, Ann. Rev. Mater. Sci., 13, 191 (1983). 

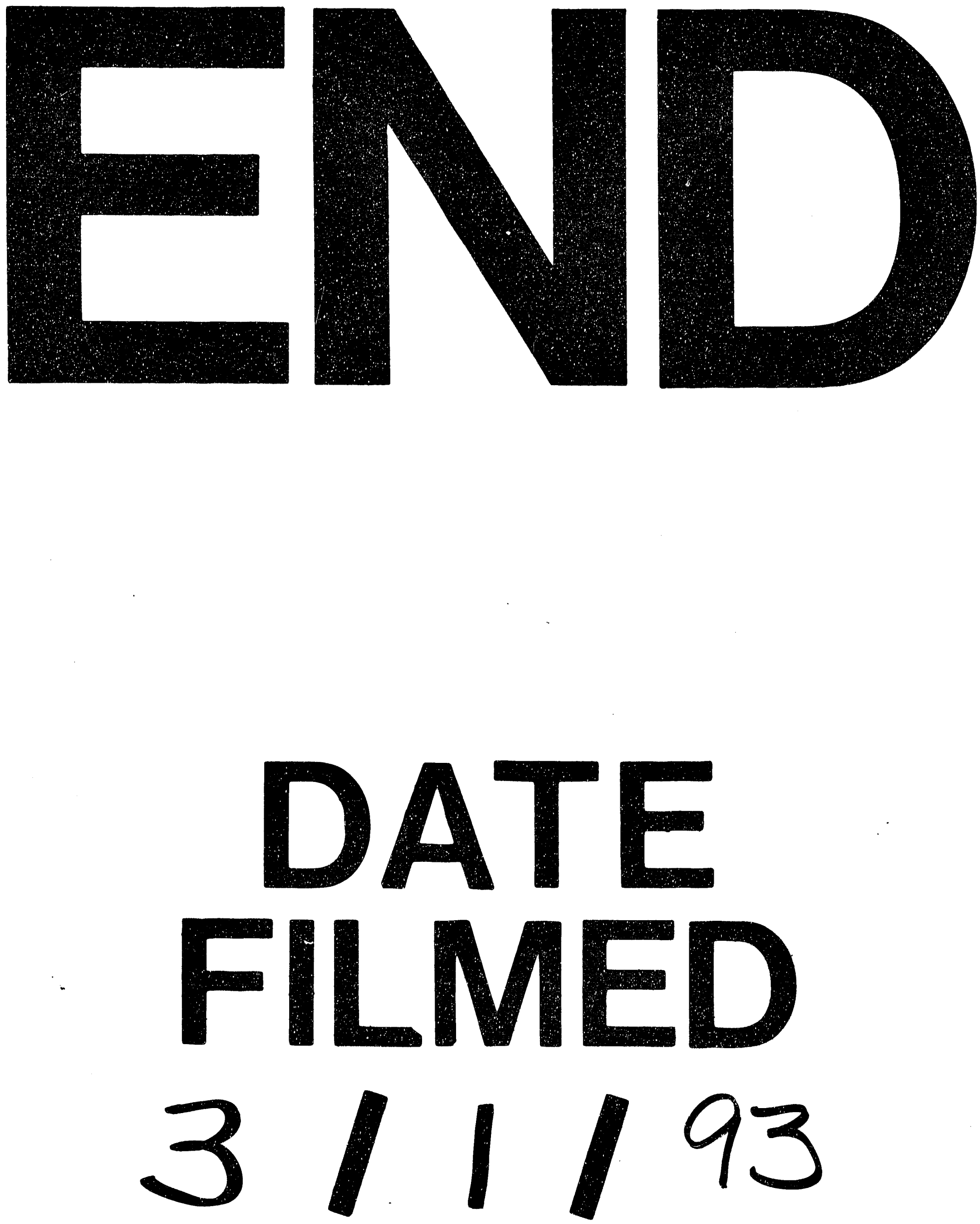
